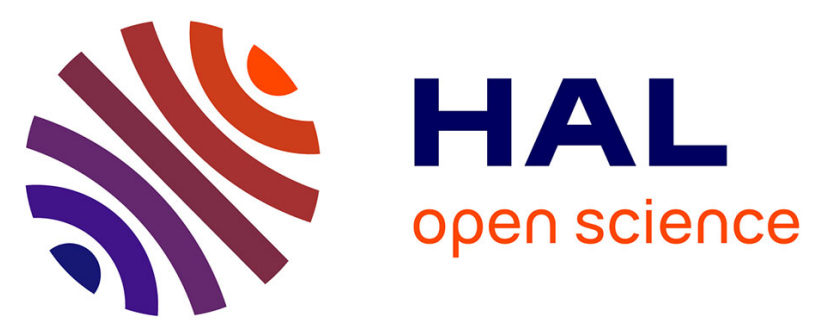

\title{
A Single Molecular Stoichiometric P-Source for Phase- Selective Synthesis of Crystalline and Amorphous Iron Phosphide Nanocatalysts
}

Florian D'accriscio, Erik Schrader, Capucine Sassoye, Mohamed Selmane, Rémi André, Sarah Lamaison, David Wakerley, Marc Fontecave, Victor Mougel, Gregoire Le Corre, et al.

\section{To cite this version:}

Florian D'accriscio, Erik Schrader, Capucine Sassoye, Mohamed Selmane, Rémi André, et al.. A Single Molecular Stoichiometric P-Source for Phase- Selective Synthesis of Crystalline and Amorphous Iron Phosphide Nanocatalysts. ChemNanoMat, 2020, 10.1002/cnma.202000198 . hal-02565354

\section{HAL Id: hal-02565354 \\ https://hal.sorbonne-universite.fr/hal-02565354}

Submitted on 6 May 2020

HAL is a multi-disciplinary open access archive for the deposit and dissemination of scientific research documents, whether they are published or not. The documents may come from teaching and research institutions in France or abroad, or from public or private research centers.
L'archive ouverte pluridisciplinaire HAL, est destinée au dépôt et à la diffusion de documents scientifiques de niveau recherche, publiés ou non, émanant des établissements d'enseignement et de recherche français ou étrangers, des laboratoires publics ou privés. 


\section{A Single Molecular Stoichiometric P-Source for Phase-}

\section{Selective Synthesis of Crystalline and Amorphous Iron}

\section{Phosphide Nanocatalysts}

Dr. Florian D'Accriscio, ${ }^{1}$ Dr. Erik Schrader, ${ }^{2}$ Dr. Capucine Sassoye, ${ }^{1}$ Mr. Mohamed

Selmane, ${ }^{4}$ Mr. Rémi F. André, ${ }^{1}$ Ms. Sarah Lamaison, ${ }^{3}$ Dr. David Wakerley, ${ }^{3}$ Prof. Marc

Fontecave, ${ }^{3}$ Prof. Victor Mougel, ${ }^{2,3}$ Mr. Grégoire Le Corre, ${ }^{2}$ Prof. Hansjörg Grützmacher, ${ }^{2}$ Prof. Clément Sanchez, ${ }^{1}$ Dr. Sophie Carenco, ${ }^{1, *}$

${ }^{1}$ Sorbonne Université, CNRS, Collège de France, Laboratoire de Chimie de la Matière Condensée de Paris, 4 place Jussieu, 75005 Paris, France

${ }^{2}$ Department of Chemistry and Applied Biosciences, ETH Zürich, Vladimir-Prelog Weg 1, CH-8093, Zürich

3 Collège de France, CNRS, Sorbonne Université, Laboratoire Chimie des Processus Biologiques, 11 place Marcelin Berthelot, 75005 Paris, France

${ }^{4}$ Sorbonne Université, Institut des Matériaux de Paris Centre, 4 place Jussieu, 75005 Paris, France

*Corresponding author. E-mail: sophie.carenco@ sorbonne-universite.fr 


\section{Abstract:}

The formation of iron phosphide nanoparticles ( $\mathrm{Fe}_{x} \mathrm{P}$ NPs) is a well-studied process. It usually uses air-sensitive phosphorus precursors such as $n$-trioctylphosphine or white phosphorus. In this study, we report the synthesis and characterization of a remarkably stable tetrakis(acyl)cyclotetraphosphane, $\mathrm{P}_{4}(\mathrm{MesCO})_{4}$. We demonstrate that this compound can be used as a stoichiometric source of $\mathrm{P}(0)$ species in order to synthesize $\mathrm{FeP}$ and $\mathrm{Fe}_{2} \mathrm{P}$ nanoparticles at only $250{ }^{\circ} \mathrm{C}$. This tunable process provides a route to monodisperse nanoparticles with different compositions and crystallinities. We combine X-Ray photoelectron spectroscopy (XPS) and atomic pair distribution function (PDF) in order to study the local order and bonding in the amorphous and crystalline materials. We show that crystalline FeP forms via an intermediate amorphous phase (obtained at a lower temperature) that presents local order similar to that of the crystalline sample. From the results of this work, a better understanding of the mechanism of the formation of amorphous and crystalline $\mathrm{Fe}_{x} \mathrm{P}$ NPs is provided which relies on the use of a stoichiometric and single P-source. We then explore the electrocatalytic properties of $\mathrm{Fe}_{x} \mathrm{P}$ nanoparticles for the hydrogen evolution reaction (HER) in acidic and neutral electrolytes. In both electrolytes, amorphous FeP is a more efficient catalyst than crystalline $\mathrm{FeP}$, itself more efficient than crystalline $\mathrm{Fe}_{2} \mathrm{P}$. Our study paves the way for a more systematic investigation of amorphous metal phosphide phases in electrocatalysis. It also shows the beneficial properties of PDF on the characterization of such nanomaterials, which is highly challenging.

Keywords: iron phosphide; nanoparticles; colloidal synthesis; atomic pair distribution function; hydrogen evolution reaction. 


\section{Introduction}

In the past decades, transition metal phosphides have raised huge interest as promising nanomaterials. ${ }^{[1,2]}$ They outperform their corresponding metal nanoparticles with respect to physical phenomena such as magnetism ${ }^{[3]}$ or optics, ${ }^{[4]}$ and show superior properties in applications relevant to energy storage,${ }^{[5-7]}$ and catalysis,${ }^{[8-15]}$ including water splitting. ${ }^{[16,17]}$ In particular, $\mathrm{Fe}_{\mathrm{x}} \mathrm{P}$ nanoparticles are among the most active catalysts containing an earthabundant metal to mediate the Hydrogen Evolution Reaction (HER) in acidic,${ }^{[8,18-21]}$ neutral, ${ }^{[8]}$ or basic media. ${ }^{[8,22-24]}$

At the macroscale, a wide range of phases, from the richest $\mathrm{P}$-containing $\mathrm{FeP}_{4}$ to the poorest $\mathrm{Fe}_{4} \mathrm{P}$, can be reached by traditional solid-state syntheses. ${ }^{[25]}$ Most of them $\left(\mathrm{Fe}_{4} \mathrm{P}, \mathrm{Fe}_{3} \mathrm{P}, \mathrm{Fe}_{2} \mathrm{P}\right.$ and $\mathrm{FeP}$ ) correspond to stable crystallographic phases under ambient conditions with close formation enthalpy. ${ }^{[26]}$ Fewer synthetic routes have been described at the nanoscale, despite significant interest in iron phosphide nanoparticles. An elegant way to synthesize such nanomaterials is to insert phosphorus into well-defined iron nanoparticles (NPs). Several commercial P-sources have been investigated as a P-donor. For example, the reaction between sodium hypophosphite $\left(\mathrm{NaH}_{2} \mathrm{PO}_{2}\right)$ and iron oxide $\left(\mathrm{Fe}_{3} \mathrm{O}_{4}\right)$ or iron oxide-hydroxide $(\mathrm{FeOOH})$ at moderate temperatures $\left(300-400{ }^{\circ} \mathrm{C}\right)$ leads to the formation of FeP nanoparticles. ${ }^{[27-29]}$ In a similar manner, Brock and coworkers showed the conversion of $\mathrm{Fe}_{3} \mathrm{O}_{4}$ NPs to FeP NPs using $n$-trioctylphosphine (TOP) as a phosphorus precursor. ${ }^{[30]}$ Similarly, triphenyl phosphite $\left(\mathrm{P}(\mathrm{OPh})_{3}\right)$ was recently used in order to phosphidize several transition metal(0) nanoparticles. ${ }^{[31]}$ Although this phosphorus source allows cheaper production of transition metal phosphide nanoparticles, it still has the same drawbacks as TOP because its low reactivity entails the use of excess reactant under elevated temperatures.

However, the formation of a single phase via a reaction in solvent is considered a challenge. ${ }^{[32]}$ TOP has since been shown as a versatile phosphorus precursor, allowing for the 
insertion of phosphorus in well-defined iron(0) NPs to access several phases $\left(\mathrm{Fe}_{2} \mathrm{P}\right.$ and FeP). ${ }^{[8,33,34]}$ In particular, Brock and coworkers studied the insertion of phosphorus from TOP into suspended $\mathrm{Fe}(0)$ nanoparticles and noticed the difficulty in obtaining phase-pure $\mathrm{FeP}$ nanoparticles from the intermediate $\mathrm{Fe}_{2} \mathrm{P}$, potentially due to the formation of a stable shell of FeP around the nanoparticle that would kinetically block the diffusion of phosphorus towards the core ${ }^{[34]}$ TOP could also be used as P-donor in an Ullmann-type coupling reaction in order to form $\mathrm{Fe}_{2} \mathrm{P}$ or FeP nanoparticles. ${ }^{[32]}$ However, these reactions require breaking $\mathrm{P}-\mathrm{C}$ bonds in order to achieve the insertion of phosphorus in $\mathrm{Fe}(0) \mathrm{NPs}$. The $\mathrm{P}-\mathrm{C}$ bond dissociation energy is around $123 \mathrm{kcal} / \mathrm{mol}$. This implies that fairly elevated temperatures $\left(300-390{ }^{\circ} \mathrm{C}\right)$ are required for synthesis together with the use of a considerable excess of phosphine, which not only serves as a source of phosphorus but also as oxygen scavenger.

It can be expected that the stoichiometric use of more reactive P-sources leads to a better control of the $\mathrm{Fe} / \mathrm{P}$ ratio. The organic precursor that was first used for this purpose was tris(trimethylsilyl)phosphine $\left(\mathrm{P}(\mathrm{TMS})_{3}\right)$, which is also successfully used as a stoichiometric P-donor for the synthesis of indium phosphide quantum dots. ${ }^{[35,36]}$ The lower dissociation energy of the $\mathrm{P}-\mathrm{Si}$ bond with respect to the $\mathrm{P}-\mathrm{C}$ bond $(72$ vs. $123 \mathrm{kcal} / \mathrm{mol})$ enabled the synthesis of $\mathrm{Fe}_{2} \mathrm{P}$ and $\mathrm{FeP}$ nanoparticles at lower temperature $\left(c a .260{ }^{\circ} \mathrm{C}\right) .{ }^{[3,37]}$ In our team, we previously showed that elemental phosphorus, $\mathrm{P}_{4}$, provides " $\mathrm{P}(0)$ " species and reacts in a stoichiometric manner with metal(0) species (complexes and nanoparticles) under mild conditions, leading to the formation of phosphide nanoparticles. ${ }^{[38,39]}$ Nevertheless, both $\mathrm{P}(\mathrm{TMS})_{3}$ and $\mathrm{P}_{4}$ are delicate to handle as they are pyrophoric and can release highly toxic $\mathrm{PH}_{3}$. This highlights the need for more reactive, yet bench-stable, stoichiometric precursors for the phase-selective synthesis of iron phosphide nanoparticles.

Another challenge of nanoparticles synthesis at moderate reaction temperature is the structural characterization of poorly crystallized and amorphous nanoparticles. ${ }^{[40-42]}$ In this respect, the 
atomic pair distribution function (PDF) is an attractive technique and can be performed using a laboratory X-ray source. ${ }^{[43-47]}$ This approach has been widely applied to liquids ${ }^{[48,49]}$ or amorphous materials ${ }^{[50-52]}$ and is proving to be a valuable and powerful tool for studying local structure at the nanoscale, ${ }^{[53]}$ both for amorphous and crystalline nanoparticles. ${ }^{[54]}$

In this work, we report the synthesis of a cyclic tetraphosphane under mild conditions. This molecule is stable in air for months and provides 4 equiv. of phosphorus atoms per molecule. Our objectives were to (i) study its ability to act as a P-source in the synthesis of iron phosphide nanoparticles under relatively mild conditions, (ii) get access to several materials with different compositions and crystallinities from a single precursor, (iii) study the local order and bonding in such amorphous and/or crystalline $\mathrm{Fe}_{x} \mathrm{P}$ materials using the atomic PDF and (iv) perform preliminary experiments in order to test the ability of the newly synthesized materials as electrocatalysts for the $\mathrm{H}_{2}$ evolution reaction.

\section{Results and discussion}

\subsection{A new P-source: Tetrakis(mesitoyl)cyclotetraphosphane}

In order to provide chemists with an alternative to highly reactive white phosphorus $\left(\mathrm{P}_{4}\right)$, we searched for an air-stable source of phosphorus. It is known that acylphosphanes and acylphosphanoxides, $\mathrm{R}_{3-x} \mathrm{P}\left(\mathrm{COR}^{\prime}\right)_{x}$ or $\mathrm{R}_{3-x} \mathrm{P}(=\mathrm{O})(\mathrm{COR})_{x}$, have unusually long $\mathrm{P}-\mathrm{C}$ bonds between the phosphorus center and the acyl group ${ }^{[55]}$ which can be easily cleaved under photolysis, making these compounds highly efficient photoinitiators. ${ }^{[56]}$ We therefore reasoned that a cyclotetraphosphane with four acyl groups like $\mathrm{P}_{4}(\mathrm{COR})_{4}$ may serve as precursor to $\mathrm{P}_{4}$, which thermally releases phosphorus due to the weakness of the $\mathrm{P}-\mathrm{P}$ bond. To the best of our knowledge, these compounds have never been rationally synthesized before. Only the structure of $\mathrm{P}_{4}\left(\mathrm{CO}^{\mathrm{t}} \mathrm{Bu}\right)_{4}$, determined by $\mathrm{X}$-ray diffraction methods, has been mentioned in a doctoral thesis without any further details. ${ }^{[57]}$ In order to develop a rational 
synthesis, we prepared mesitoyl phosphane by reacting the double salt $\left[\mathrm{NaPH}_{2} \times\right.$ $\left.\mathrm{Na}(\mathrm{OtBu})_{x}\right]^{[58]}$ with mesitoylmethylester (Figure 1). $\mathrm{H}_{2} \mathrm{P}-\mathrm{COMes}$ was obtained as a yellow oil in good yield and reacted without further purification with hexachloroethane and trimethylamine as $\mathrm{HCl}$ scavenger. Indeed, the desired product $\mathrm{P}_{4}(\mathrm{COMes})_{4}$ was obtained as a yellow powder although in rather low isolated yield $(10 \%) . \mathrm{P}_{4}(\mathrm{COMes})_{4}$ is remarkably stable in air and can be stored for months without any special precautions. Under inert atmosphere, thermal decomposition of the compound showed an onset temperature at $244.6{ }^{\circ} \mathrm{C}$. Mass spectrometry and ${ }^{31} \mathrm{P}$ NMR of the volatile thermolysis products revealed the presence of $\mathrm{P}_{4}$ (Figure S7 and Figure S8).

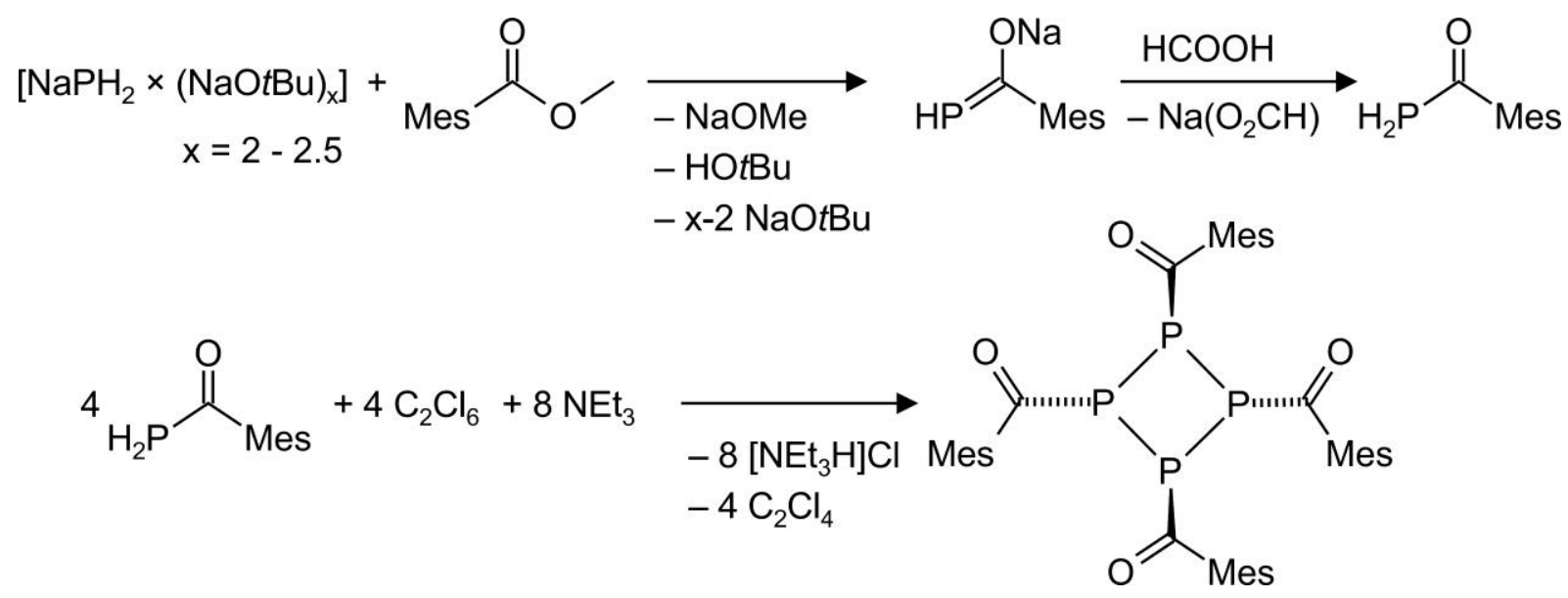

Figure 1: Synthesis of $\mathrm{P}_{4}(\mathrm{MesCO})_{4}$.

The purity and identity of the compound was verified by NMR spectroscopy. In the ${ }^{1} \mathrm{H}$ NMR spectrum (Figure S3), the presence of the mesitoyl groups was indicated by three resonances at $\delta=6.63 \mathrm{ppm}, 2.25 \mathrm{ppm}$ and $1.92 \mathrm{ppm}$, integrating for 8,12 and 24 protons, respectively. In the ${ }^{31} \mathrm{P}$ and ${ }^{31} \mathrm{P}\{1 \mathrm{H}\}$ spectra, only one singlet at $\delta=-44.7 \mathrm{ppm}$ was observed suggesting four magnetically equivalent phosphorus atoms (Figure S5). After recrystallization from a saturated THF solution at $-30{ }^{\circ} \mathrm{C}$, single crystals of $\mathrm{P}_{4}(\mathrm{COMes})_{4}$ were obtained which were subjected to an X-ray diffraction analysis (Table S1). The plot of the structure is shown in 
Figure 2. The $\mathrm{P}_{4}$ ring is folded by $32.5(1)^{\circ}$ and the mesitoyl substituents show an alternating up-down-up-down position with respect to the best plane through the $\mathrm{P}_{4}$ ring. The $\mathrm{P}-\mathrm{P}$ bond lengths, between 2.21 and $2.23 \AA$, are within the typical range of P-P single bonds. As

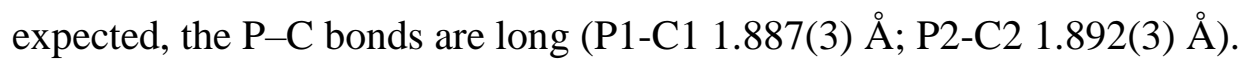

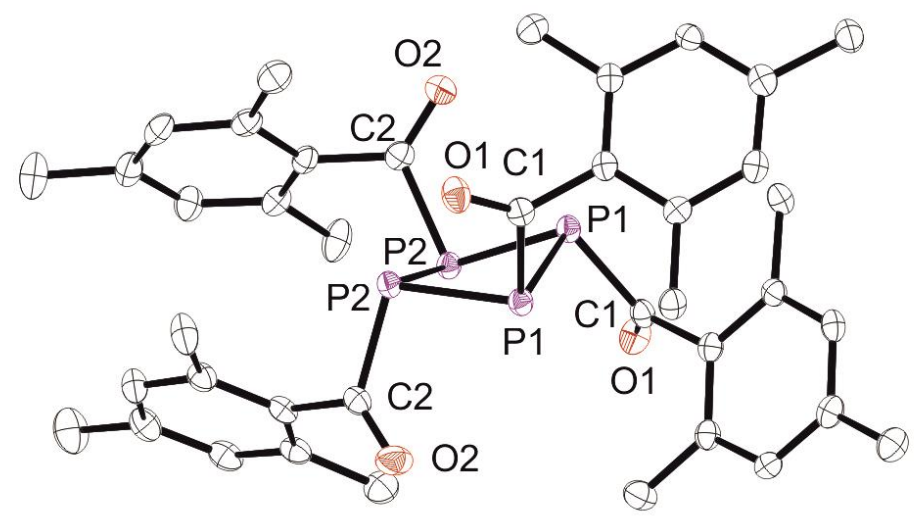

Figure 2: Structure of $\mathrm{P}_{4}(\mathrm{MesCO})_{4}$ in the crystal (50\% thermal ellipsoids). Hydrogen atoms on the mesitoyl substituents are omitted for clarity. Selected bond lengths $[\AA ̊]$ and angles $\left[^{\circ}\right]$ : $\mathrm{C}(1)-\mathrm{P}(1)$ 1.887(3), $\mathrm{C}(2)-\mathrm{P}(2)$ 1.892(3), $\mathrm{P}(1)-\mathrm{P}(2)-\mathrm{P}(1) 32.5(1)$.

\subsection{Formation of crystalline $\mathrm{FeP}$ and $\mathrm{Fe}_{2} \mathrm{P}$ nanoparticles}

$\mathrm{P}_{4}(\mathrm{MesCO})_{4}$ was investigated as a reagent for the preparation of iron phosphide nanoparticles, being an air stable and user-friendly alternative to $\mathrm{P}_{4}$.

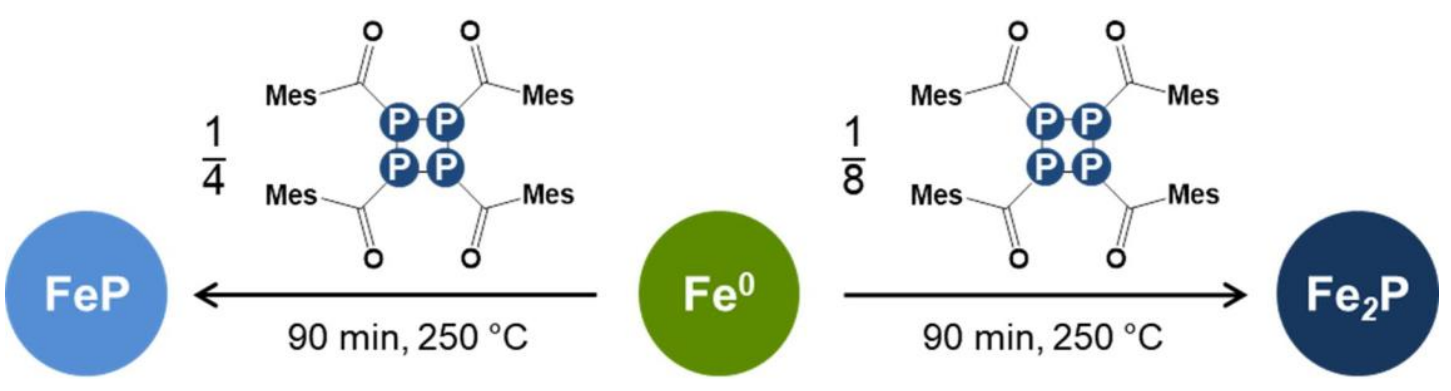

Figure 3: Proposed conversion of iron nanoparticles into iron phosphides with $\mathrm{P}_{4}(\mathrm{MesCO})_{4}$ as a stoichiometric P-source. 
Monodisperse iron nanoparticles were prepared according to a modified procedure previously described by Peng et al. (see Experimental Section for further details). ${ }^{[59]}$ This synthesis yields monodisperse $\mathrm{Fe}(0)$ nanoparticles with a mean diameter of $8.4 \pm 0.6 \mathrm{~nm}$ (Figure S9). In a typical procedure to form iron phosphides (Figure 3), these Fe(0) NPs were directly reacted, without being isolated from their native solution, at $250{ }^{\circ} \mathrm{C}$ for $90 \mathrm{~min}$ with a stoichiometric amount of $\mathrm{P}_{4}(\mathrm{MesCO})_{4}$ vs. the targeted phase (i.e. $0.25 / x$ equiv., with $x=1$ for $\mathrm{FeP}$ and $x=2$ for $\left.\mathrm{Fe}_{2} \mathrm{P}\right)$. The reaction was performed under inert atmosphere. A white smoke formed in the media at $c a .100{ }^{\circ} \mathrm{C}$, indicating a reaction between $\mathrm{P}_{4}(\mathrm{MesCO})_{4}$ and the pre-formed $\mathrm{Fe}(0)$ nanoparticles. The product was then isolated and washed in air by centrifugation and precipitation using a hexane/acetone (1:5) solvent mixture, and finally dried under $\mathrm{N}_{2}$.

Powder X-ray diffraction (PXRD) analysis revealed the formation of crystalline FeP (PDF card [03-065-2595]) and $\mathrm{Fe}_{2} \mathrm{P}$ (PDF card [00-051-0943]) nanoparticles, for $x=1$ and $x=2$ respectively (Figure 4A). According to the Scherrer equation applied to the (212) reflection (at $c a .56^{\circ}$ ), a crystallite size of $7 \mathrm{~nm}$ was obtained for the FeP nanoparticles. In the case of $\mathrm{Fe}_{2} \mathrm{P}$, the broadness of the peaks on the diffractogram indicates smaller crystalline domains; the high baseline of the diffraction pattern also suggests the possible presence of an additional amorphous phase.

Transmission Electron Microscopy (TEM) carried out on FeP revealed the formation of spherical hollow FeP nanoparticles of about $8.9 \pm 0.9 \mathrm{~nm}$ in diameter. Most of them are single-crystals, despite their hollow shape with a wall of $2.5 \mathrm{~nm}$ thickness. This is consistent with the PXRD pattern (Figure 4B) because the characteristic crystalline size of these nanoparticles is not the wall thickness but the overall object. Selected-area electronic diffraction (SAED) performed on a few nanoparticles confirmed their crystallinity, as the dspacing of the diffraction rings matched well those of the FeP reference structure (see Figure 
S10). This result is consistent with the work previously reported in our team ${ }^{[38]}$ and others ${ }^{[8,34,37]}$ when $\mathrm{P}_{4}$, TOP or TOPO were used as a P-donor.
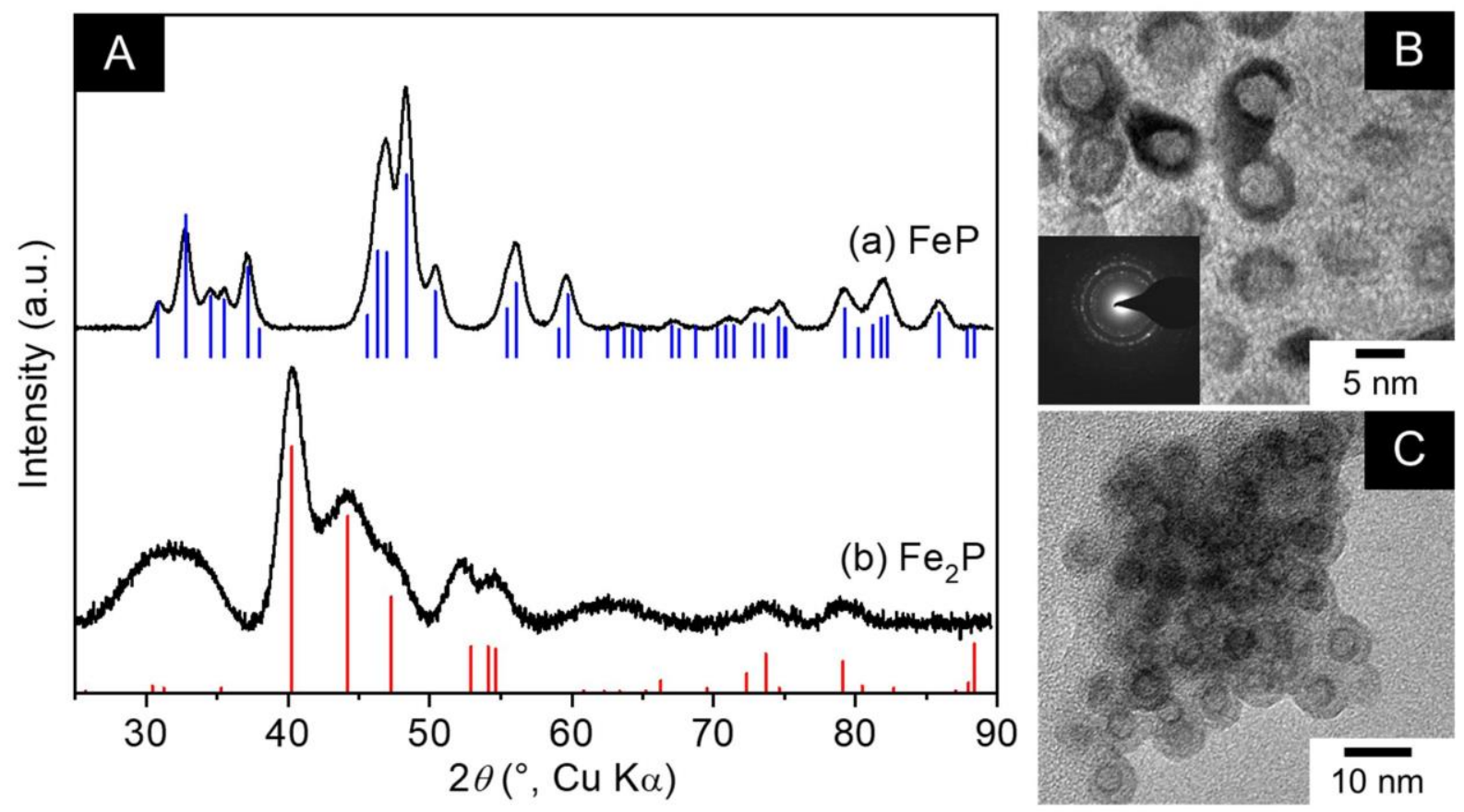

Figure 4: (A) Powder X-Ray diffractograms of (a) $\mathrm{FeP}$ and (b) $\mathrm{Fe}_{2} \mathrm{P}$, synthesized at $250{ }^{\circ} \mathrm{C}$. Reference patterns are plotted below the experimental ones: FeP in blue (PDF card 03-0652595) and $\mathrm{Fe}_{2} \mathrm{P}$ in red (PDF card 00-051-0943). (B) TEM of FeP (inset: SAED). (C) TEM of $\mathrm{Fe}_{2} \mathrm{P}$ nanoparticles.

TEM of $\mathrm{Fe}_{2} \mathrm{P}$ showed an unexpected feature of the nanoparticles (Figure 4C). It revealed another type of spherical hollow nanoparticles with two shells. The inner shell is darker than the outside one, suggesting two different phases such as $\mathrm{Fe}_{2} \mathrm{P}$ and an oxygen-containing shell, respectively. Moreover, the inner shell is thin (ca. $1 \mathrm{~nm}$ in thickness), which is in agreement with the PXRD pattern of $\mathrm{Fe}_{2} \mathrm{P}$, though SAED and HRTEM did not provide exploitable data at this scale.

In order to further analyze this thin shell, XPS was performed on the nanoparticles on the P $2 p$ (Figure $5 \mathrm{~A}$ ), Fe $2 \mathrm{p}_{3 / 2}$ (Figure $5 \mathrm{~B}$ ) and $\mathrm{Fe} 3 \mathrm{p}$ regions (Figure $5 \mathrm{C}$ ). In the $\mathrm{P} 2 \mathrm{p}$ region, four 
doublets were identified (see Supporting Information and Table S4 for detailed fitting procedure). $\mathrm{P} 2 \mathrm{p}$ region was fitted with four doublets with a splitting of $0.86 \mathrm{eV}$, and only the values of the $\mathrm{P} 2 \mathrm{p}_{3 / 2}$ are discussed below. For FeP (spectrum a), components at 129.4 (gray), 130.4 (red), 132.6 (dark green) and $133.3 \mathrm{eV}$ (light green) were identified as an optimized combination to fit the spectrum. According to their binding energies (B.E.), they were attributed to phosphide, $\mathrm{P}(0), \mathrm{P}(\mathrm{III})$ and $\mathrm{P}(\mathrm{V})$ species respectively, based on the literature. ${ }^{[60-}$ 63] The same components with B.E. within less than $1 \mathrm{eV}$ shift were identified for $\mathrm{Fe}_{2} \mathrm{P}$ (spectrum b). On both spectra, pie chart insets represent the speciation of the species, based on the relative area of the components.

The phosphide component was naturally attributed to iron phosphide species (regardless of the crystal structure). The $\mathrm{P}(0)$ species was barely detectable for $\mathrm{Fe}_{2} \mathrm{P}$ and slightly more intense for FeP: we tentatively propose that it corresponds to phosphorus atoms in a poorly crystallized region of the iron phosphides, as will be discussed in the next section. The $\mathrm{P}(\mathrm{V})$ and P(III) components were interpreted respectively as surface phosphate and phosphite. They could have formed as a result of the exposure to air of the nanoparticles, or due to the presence of oxygen from the mesitoyl moiety of the phosphorus precursor.

Comparison of $\mathrm{FeP}$ and $\mathrm{Fe}_{2} \mathrm{P}$ indicated that both surfaces exhibit iron phosphide, but that those of $\mathrm{Fe}_{2} \mathrm{P}$ were more oxidized, as it mainly showed oxidized phosphorus species. Consistently, the $\mathrm{Fe} 2 \mathrm{p}_{3 / 2}$ region (Figure $5 \mathrm{~B}$ ) showed mostly oxidized iron (red dotted line at $711 \mathrm{eV}$ ) for $\mathrm{Fe}_{2} \mathrm{P}$, while reduced iron (gray dotted line at $707 \mathrm{eV}$ ) was more intense in $\mathrm{FeP}$. The $\mathrm{Fe} 3 \mathrm{p}$ region confirmed this trend with a higher contribution of the low B.E. component for $\mathrm{FeP}$ than for $\mathrm{Fe}_{2} \mathrm{P}$ (see ESI for the fitting procedure details). 

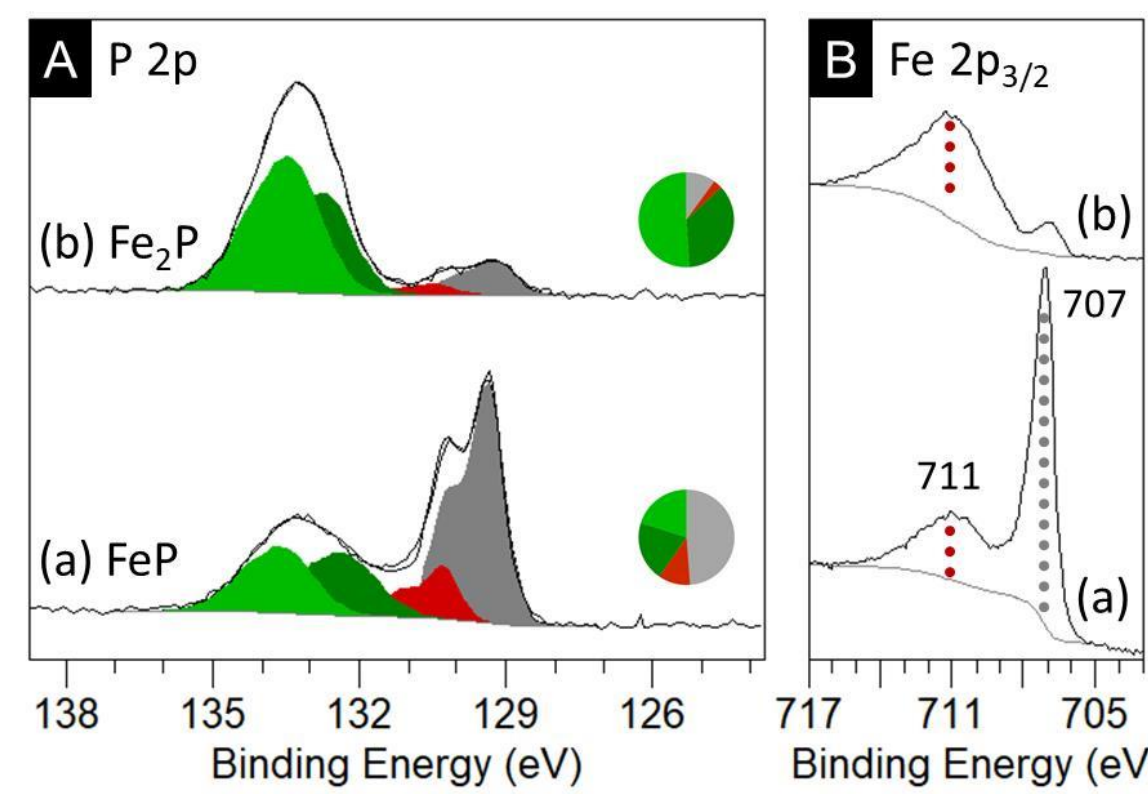

Binding Energy (eV)

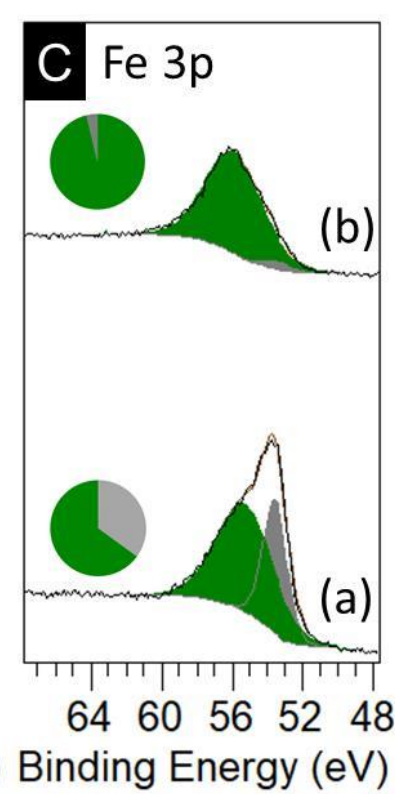

Figure 5: X-ray photoelectron spectroscopy on the $\mathrm{FeP}$ (a) and $\mathrm{Fe}_{2} \mathrm{P}$ (b) nanoparticles powders. (A) $\mathrm{P} 2 \mathrm{p}$ region fitted with four doublets. (B) $\mathrm{Fe} 2 \mathrm{p}_{3 / 2}$ region with dotted line as a guide for the eye: gray line for $\mathrm{Fe}(0)$ and red line for iron oxide satellite. (C) $\mathrm{Fe} 3 \mathrm{p}$ region fitted with two components. Pie chart insets represent the relative area of the components of each spectrum, with the same color codes as in the spectra: in the $\mathrm{P} 2 \mathrm{p}$ region, phosphide (gray), $\mathrm{P}(0)$ (red), $\mathrm{P}(\mathrm{III})$ (dark green), $\mathrm{P}(\mathrm{V})$ (light green), and in the Fe $3 \mathrm{p}$ region, iron phosphide (gray), oxidized iron (dark green).

Based on XPS, TEM and XRD, we propose that the light-gray shell observed on $\mathrm{Fe}_{2} \mathrm{P}$ by TEM is composed of oxidized iron and phosphorus species in an amorphous state. Such species were also detected, to a much lesser extent, on the FeP nanoparticles, without forming a shell thick enough to be observed by TEM. In terms of composition, $\mathrm{Fe}_{2} \mathrm{P}$ (slightly pyrophoric) is between pure Fe (highly pyrophoric) and FeP (not pyrophoric): we propose that the higher the phosphorus content, the higher the stability of the compound toward oxygen sources, such as ambient atmosphere. 


\subsection{Amorphous nanoparticles as a key intermediate for the formation of crystalline materials}

We then tried to study a possible mechanism of the iron phosphide formation. The hollow morphology seemed to indicate an insertion of phosphorus from the outside to the inside of the nanoparticles, occurring while iron was migrating from the inside to the outside (so-called "nanoscale Kirkendall effect"). ${ }^{[64]}$

In order to catch reaction intermediates, reactions were performed either with less P-donor or at a lower temperature. With a lower stoichiometry of $\mathrm{P}_{4}(\mathrm{MesCO})_{4},(x=3$ and $x=4$, targeting $\mathrm{Fe}_{3} \mathrm{P}$ and $\mathrm{Fe}_{4} \mathrm{P}$ phase, respectively) and the same temperature as previously $\left(250^{\circ} \mathrm{C}\right)$, partially magnetic black powders were obtained. In the case of $x=3$, the solid turned brownish after a few days on the bench in air. Contrary to what was observed in the synthesis of P-richer phases, only amorphous materials were synthesized under these conditions (Figure 6A-b and c). Besides, the synthesis for $x=1$ and $x=2$ (aiming at $\mathrm{FeP}$ and $\mathrm{Fe}_{2} \mathrm{P}$ phase, respectively) at lower temperature $\left(180^{\circ} \mathrm{C}\right)$ also yielded amorphous materials, as showed by PXRD patterns (Figure 6A-d and f). 


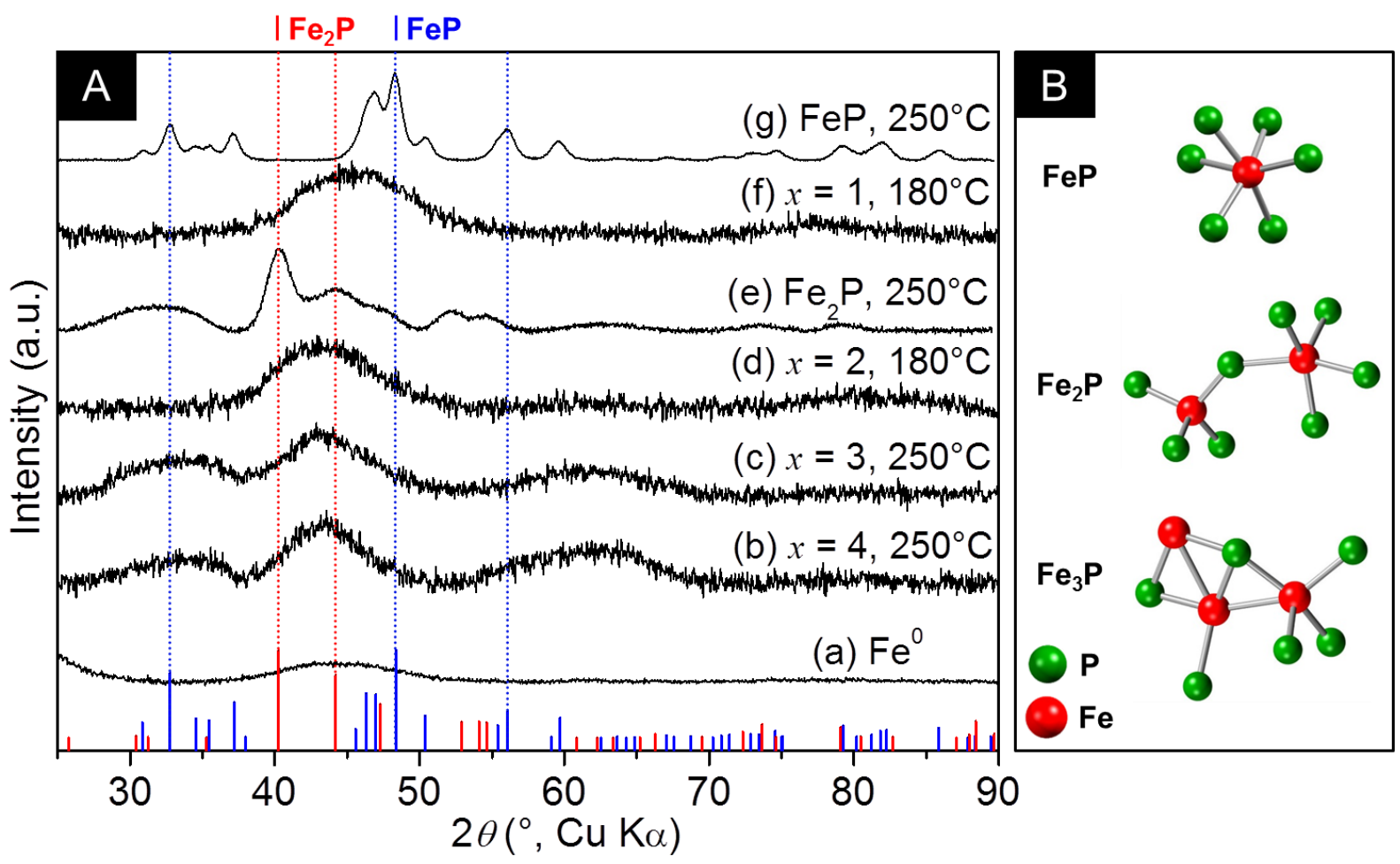

Figure 6: (A) Overlay of diffractograms of the starting $\mathrm{Fe}(0)$ and all targeted $\mathrm{Fe}_{x} \mathrm{P}$ nanoparticles synthesized at various temperatures; (B) theoretical local order of FeP (top), $\mathrm{Fe}_{2} \mathrm{P}$ (middle) and $\mathrm{Fe}_{3} \mathrm{P}$ (bottom) phase showing each independent $\mathrm{Fe}$ atom surrounded with its $P$.

In these two cases (lower reaction temperature or lower stoichiometry of phosphorus), because no crystalline phase with determined Fe/P ratio could be identified, PXRD did not indicate if the reaction was quantitative vs. the P-source. Nonetheless, ${ }^{31} \mathrm{P}\left\{{ }^{1} \mathrm{H}\right\}$ NMR analysis of the supernatant collected after the first centrifugation for all reactions did not show any signals, suggesting that all $\mathrm{P}_{4}(\mathrm{MesCO})_{4}$ (characterized by a singlet at $-44.7 \mathrm{ppm}$ ) was consumed during the reaction and that no other phosphorus-containing by-products were formed in significant amounts. This is consistent with a quantitative reaction of $\mathrm{P}_{4}(\mathrm{MesCO})_{4}$ with the iron(0) nanoparticles.

To confirm this result, element compositions of the powders prepared at $250{ }^{\circ} \mathrm{C}$ were measured by X-ray fluorescence measurements (XRF) (Table S2). The molar ratios Fe/P are 
consistent with the expected stoichiometries, with lesser and lesser amount of phosphorus detected from the sample series from $\mathrm{FeP}$ to the $\mathrm{Fe}_{4} \mathrm{P}$. Absolute values are slightly larger than expected for all the samples (eg. $\mathrm{Fe} / \mathrm{P}=2.1$ for the $\mathrm{Fe}_{2} \mathrm{P}$ sample). We attribute this systematic bias to the presence of a thin amorphous layer oxide especially for the iron-rich nanoparticles. These results were further confirmed by EDS (Figure $\mathrm{S} 17$ and $\mathrm{S} 18$ ) for $\mathrm{FeP}$ and $\mathrm{Fe}_{2} \mathrm{P}$ crystalline nanoparticles.

With the variation of composition a change in the local environment of Fe and $\mathrm{P}$ should arise, not only for the crystalline samples (Figure 6A-e and g) but also for the amorphous ones. We could expect the local environment to be close of these of the corresponding crystalline phases (showed on Figure 6B). In particular, the asymmetric units of $\mathrm{FeP}, \mathrm{Fe}_{2} \mathrm{P}$ and $\mathrm{Fe}_{3} \mathrm{P}$ crystal structures present a different $\mathrm{Fe}-\mathrm{P}$ connectivity as well as different inter-atomic distances (Table S3 and Figure 6B).

\subsection{Local structure and bonding in FeP crystalline and amorphous nanoparticles}

In order to better characterize the amorphous powders, we employed atomic Pair Distribution Function (PDF) analysis. ${ }^{[53,65-67]}$ This analysis provides information regarding the local structure and inter-atomic distances even for non-crystalline materials. It consists in the analysis of the total X-Ray scattering by way of Fourier Transform (see supporting information for details), which leads to the $G_{\text {exp }}(r)$ function. ${ }^{[68]}$ A similar function $\left(G_{\text {sim }}(r)\right)$ can be calculated from a structural model as the probability of finding a pair of atoms separated by the distance $r$ (in summary, this is the histogram of all the atomic distances in the material). ${ }^{[69]}$ Comparison of $\mathrm{G}_{\text {sim }}(\mathrm{r})$ and $\mathrm{G}_{\mathrm{exp}}(\mathrm{r})$ leads to the validation of the structural model. The discussions below will be focused on the lower $r$ values, typically from 1 to $3 \AA$ : peaks in this region correspond to correlation that emanate from single bonds (eg. Fe-P) and are thus much easier to interpret than the peaks at higher $r$ values. However, data are presented over 
the whole range from 0 to $20 \AA$ A: for crystalline compounds, correlation peaks are still intense at high $\mathrm{r}$, while for amorphous compounds, the overall signal decreases with $\mathrm{r}$.

\subsubsection{Validation of the methodology using crystalline FeP nanoparticles}

To validate our methodology, we first performed PDF analysis on crystalline FeP nanoparticles synthesized with $x=1$ at $250{ }^{\circ} \mathrm{C}$ (Figure S11). In this case, the extracted $\mathrm{G}_{\text {exp }}(\mathrm{r})$ matched with the calculated $\mathrm{G}_{\text {sim }}(\mathrm{r})$ from FeP crystallographic data (PDF card [03-065-2595]), taking into account the finite size of the crystal (hence, adding an attenuation factor to the function). Further refinements (cell parameters, atomic positions and isotropic thermal parameters) led to a fairly good fit $\left(\mathrm{R}_{\mathrm{w}}=11.4 \%\right)$, confirming the structure of $\mathrm{FeP}$ and the absence of other amorphous impurities. This shows that the crystalline nanoparticles of FeP contained atoms in an environment that was similar to that of the bulk FeP phase.

\subsubsection{Identification of three significant features in the G(r) curves of amorphous powders}

Before analyzing the amorphous sample, we simulated the G(r) curves from known crystallographic structures in order to identify the most significant features on the experimental curves.

Simulations of PDF were performed from $\mathrm{FeP}, \mathrm{Fe}_{2} \mathrm{P}$ and $\mathrm{Fe}_{3} \mathrm{P}$ crystallographic data (PDF card [03-065-2595], [00-051-0943] and [04-004-2129], respectively), using the calculated broadening and attenuation coefficients from the previous crystalline $\mathrm{FeP}$ refinement (Figure S12). This allowed us to simulate G(r) of amorphous samples using a smaller coherent size (Figure S13), rather than of extended crystals. At very short range (bellow $5 \AA$ ), simulated amorphous and crystalline G(r) are similar. Comparison between the three calculated G(r) of Figure S13 clearly attests of differences between the three structures, from local to larger order. The analysis of the distances distribution in the structures (Table S3) led to the 
identification of the shortest distances as Fe-P bonds: $2.30 \AA$ for $\mathrm{FeP}, 2.22 \AA$ for $\mathrm{Fe}_{2} \mathrm{P}$ and $2.36 \AA$ for $\mathrm{Fe}_{3} \mathrm{P}$. Concerning $\mathrm{Fe}_{2} \mathrm{P}$, the so-called calculated "Fe-Fe peak" at $2.53 \AA$ is in fact a mixed of $\mathrm{Fe}-\mathrm{Fe}$ and $\mathrm{Fe}-\mathrm{P}$ distances that are closer. The envelope presents a maximum slightly out of Fe-Fe calculated range $(2.58-2.70 \AA)$. Even if not fully deconvoluted, this peak at $2.53 \AA$ can be considered as characteristic of the $\mathrm{Fe}_{2} \mathrm{P}$ structure. As a consequence, the first experimental peak at $2.30 \AA$ from the crystalline $F e P G_{\text {exp }}(r)$ can be attributed to $\mathrm{Fe}-\mathrm{P}$ bonds; the second peak at $2.70 \AA$ to $\mathrm{Fe}-\mathrm{Fe}$ bonds in $\mathrm{FeP}$. As a guide to the eye, these two significant features were plotted as dashed lines, resp. in blue and in light green, on Figure 7A. Regarding $\mathrm{Fe}_{2} \mathrm{P}$, the significant feature at $2.53 \AA$ is indicated by a dashed line in dark green on Figure 7A.

\subsubsection{Interpretation of experimental $G(r)$ curves for amorphous samples prepared at $180^{\circ} \mathrm{C}$}

As expected, the experimental PDF analysis of the amorphous nanoparticles synthesized for $x=1$ at $180{ }^{\circ} \mathrm{C}$ provided a $\mathrm{G}_{\exp }(\mathrm{r})$ function that was rapidly decreasing since the order in the crystal structure is lower than for crystalline materials (Figure 7A-c and d). Moreover, PDF calculated peak positions for amorphous materials (Figure S13) clearly show that the Fe-Fe and Fe-P identification cited above for crystalline material still stands (Table S3), leading to the possible identification of the local structure of amorphous materials. A broad peak was observed at $2.30 \AA$ A (blue dashed lines on Figure 7A and Figure S15), similar to that of the Fe$\mathrm{P}$ bond in the FeP phase. Overall, the calculated $\mathrm{G}_{\text {sim }}(\mathrm{r})$ curve from the FeP model and the $G_{\text {exp }}(r)$ looked alike, confirming the formation of an amorphous phase that has the same local order than the crystalline FeP phase.

Like the crystalline nanoparticles prepared at $250{ }^{\circ} \mathrm{C}$, these amorphous nanoparticles show a hollow morphology and a mean diameter of $7.7 \pm 0.6 \mathrm{~nm}$ (Figure 7B and Figure S15B and C). 
This indicates that the formation of crystalline FeP nanoparticles occurs first through the formation of amorphous hollow FeP nanoparticles at $180{ }^{\circ} \mathrm{C}$ (with a local order already similar to crystalline FeP). It is only after this step that the crystallization is completed at $250{ }^{\circ} \mathrm{C}$. This mechanism is in line with the fact that most of the final nanoparticles are singlecrystals, despite their hollow nature. This is schematized on the top route of Figure 8: under bracket is represented the early stage of phosphorus insertion in the Fe nanoparticles. The route on the top of the scheme represents the two steps discussed above: first, the formation of an amorphous hollow nanoparticle, second, its crystallization.

Regarding nanoparticles prepared with $x=2$ at $180{ }^{\circ} \mathrm{C}$, TEM reveals a plain morphology (Figure 7C). The inner shell is darker than the outer one, suggesting two different phases, such as an iron phosphide phase and an oxidized amorphous phase, respectively. PDF analysis revealed two distinct peaks (Figure $7 \mathrm{~A}-\mathrm{a}$ and b, Figure S16): the major peak at $2.57 \AA$ (green dashed lines on both figures) is in agreement with a $\mathrm{Fe}-\mathrm{Fe}$ bond from the $\mathrm{Fe}_{2} \mathrm{P}$ structure, whereas the minor one at $2.03 \AA$ (Figure $\mathrm{S} 16$, purple dashed line) can be attributed to a $\mathrm{Fe}-\mathrm{O}$ bond in an unidentified phase resembling iron oxide. This attribution is consistent with the TEM observation.

The overall mechanism for $x=2$ is thus slightly different from that for $x=1$. After a similar initiation step of phosphorus insertion through the surface of Fe nanoparticles (under bracket in Figure 8), plain amorphous nanoparticles are formed at $180{ }^{\circ} \mathrm{C}$ (bottom route of the figure), with a local order close to these of crystalline $\mathrm{Fe}_{2} \mathrm{P}$. The nanoparticles crystallization is achieved at $250{ }^{\circ} \mathrm{C}$. $\mathrm{Fe}_{2} \mathrm{P}$ being more iron-rich than $\mathrm{FeP}$, its sensitivity to surface oxidation is higher, which explains the formation of a thicker layer of oxidized species. This layer is poorly defined, and probably a mixture of oxides and phosphates, based on PDF (simulated PDF of phosphates are presented in Figure S14) and XPS (discussed above). 


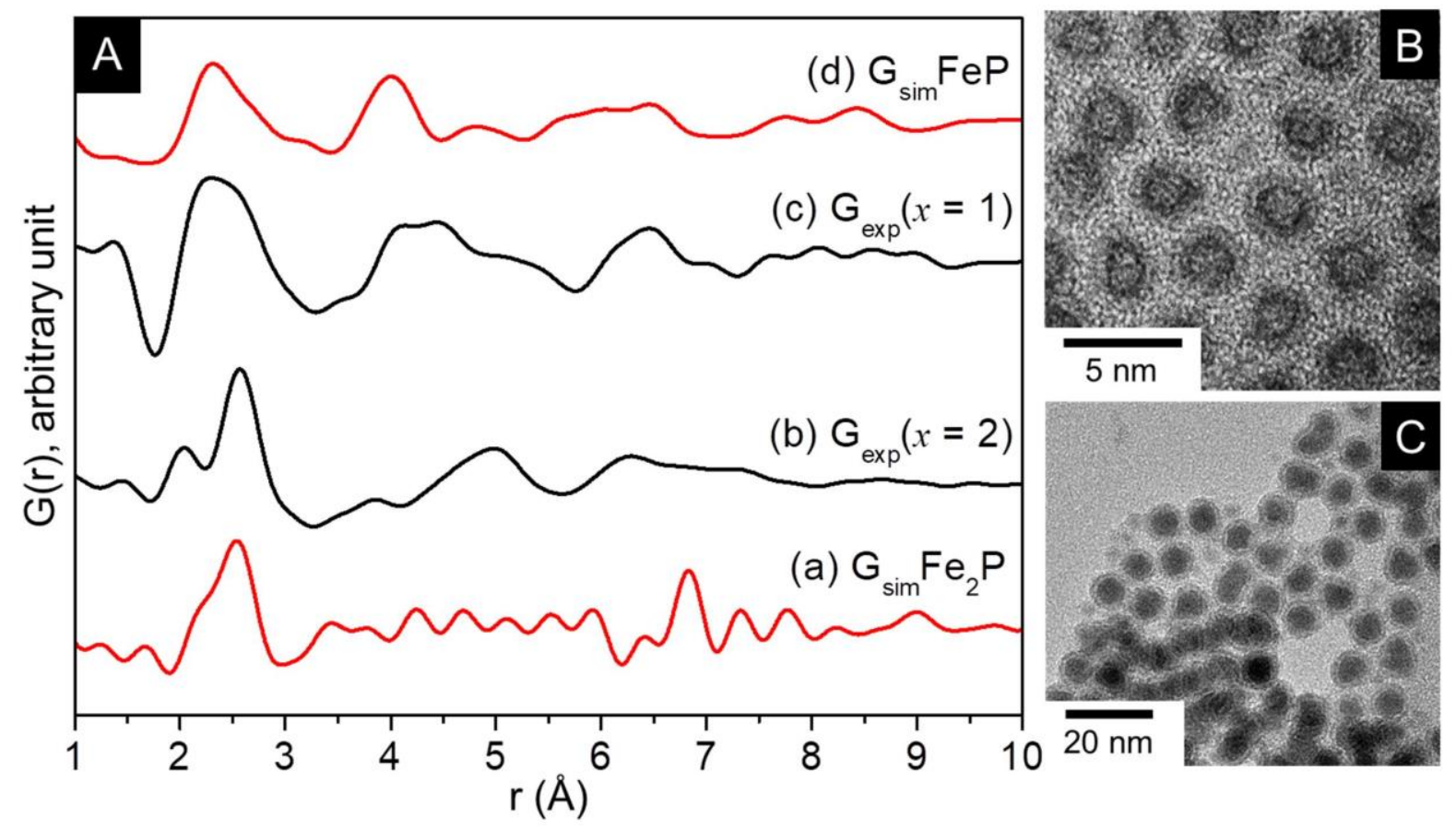

Figure 7: (A) PDF obtained (a) theoretically for $\mathrm{Fe}_{2} \mathrm{P}$, (b) experimentally for $x=2$ at $180{ }^{\circ} \mathrm{C}$, (c) experimentally for $x=1$ at $180{ }^{\circ} \mathrm{C}$ and (d) theoretically for FeP; (B) TEM image of the nanoparticles obtained for $x=1$ at $180{ }^{\circ} \mathrm{C}$ presented with enhanced contrast for better observation of the core/shell structure; (C) TEM image of the nanoparticles obtained for $x=2$ at $180{ }^{\circ} \mathrm{C}$.

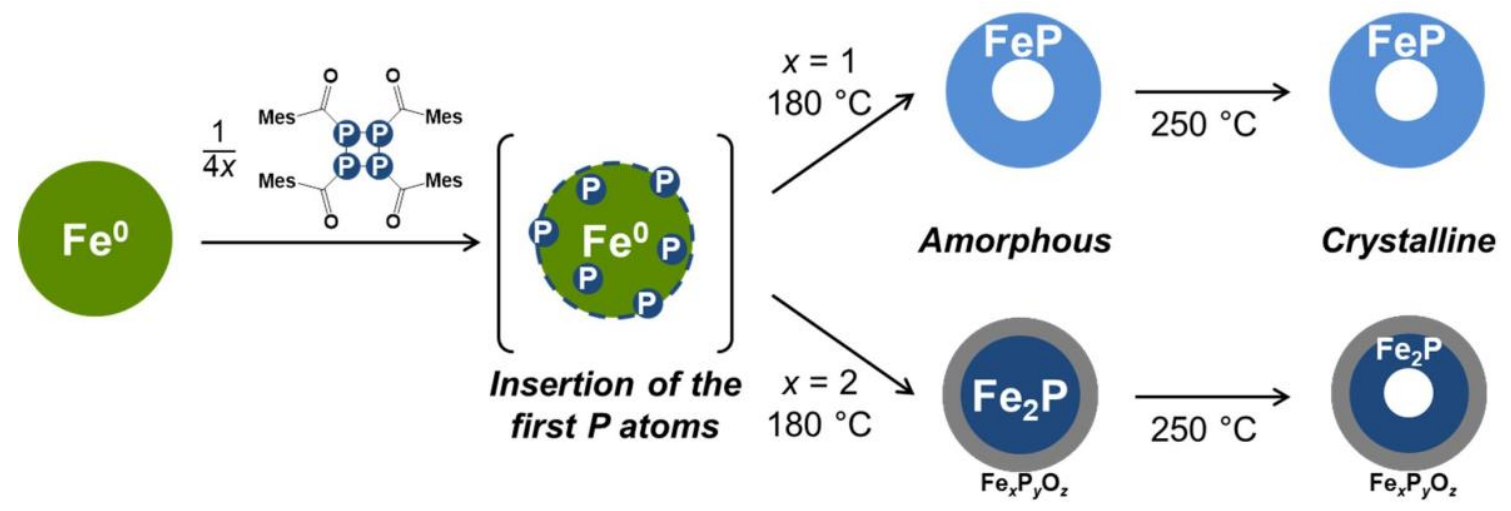

(a) 
Figure 8: Proposed mechanism for the formation of (a) FeP and (b) $\mathrm{Fe}_{2} \mathrm{P}$ NPs. The colors correspond to composition, regardless of the crystallinity: green for metallic iron, dark blue for $\mathrm{Fe}_{2} \mathrm{P}$, light blue for $\mathrm{FeP}$, gray for oxygen-containing phase.

As a partial conclusion, we can thus affirm that, both for $x=1$ and $x=2$, the formation of iron phosphides occurs first through insertion of phosphorus in the iron nanoparticles (Figure 8, intermediate under bracket, not observed in this study). This insertion is completed forming an amorphous phase (Figure $\mathbf{8}$ routes (a) and (b)), then followed by the crystallization of the phosphide phase. Interestingly, the intermediate amorphous state at $180{ }^{\circ} \mathrm{C}$ already show the local order of the final crystalline state, whether it is $\mathrm{Fe}_{2} \mathrm{P}$ or FeP. Moreover, the concomitant hole formation, due to the outward migration of iron, did not significantly affect this mechanism.

\subsection{Comparative electrocatalytic activity of the nanoscaled iron phosphides}

At this stage, $\mathrm{Fe}_{x} \mathrm{P}$ nanoparticles of similar diameter were available to be compared in terms of electrocatalytic activities, with two variable parameters: their stoichiometry ( $x=1$ or 2$)$ and their crystallinity. We selected amorphous and crystalline $\mathrm{FeP}$, as well as crystalline $\mathrm{Fe}_{2} \mathrm{P}$ as electrocatalysts of interest for the reduction of protons in acidic and neutral electrolytes.

An ink of nanoparticles ( $2 \mathrm{mg}$ nanoparticles in $200 \mu \mathrm{L}$ isopropanol) was drop-casted onto a carbonaceous gas-diffusion-layer support $\left(\mathrm{GDL}, 1 \mathrm{~cm}^{2}\right)$. The as-prepared electrodes were initially tested in benchmark acidic conditions for $\mathrm{H}_{2}$ evolution $\left(\mathrm{H}_{2} \mathrm{SO}_{4}, 1.0 \mathrm{M}\right) .{ }^{[70]} \mathrm{An}$ activation procedure $^{[23]}$ was applied to all catalysts by carrying out a controlled potential electrolysis at $-1.0 \mathrm{~V} v s$. RHE for 1 hour, after which the measurement of catalytic activity was performed.

Linear sweep voltammograms (LSV) and controlled current electrolysis at $-10 \mathrm{~mA} . \mathrm{cm}^{-2}$ are presented in Figure 9A and B, respectively. All the samples displayed catalytic activity, with a 
catalytic onset overpotential $(\eta)$ for proton reduction lower than that of the bare GDL support (Figure 9A). The LSV data highlight that the amorphous FeP is much more efficient than the two crystalline $\mathrm{FeP}$ and $\mathrm{Fe}_{2} \mathrm{P}$ phases, as it presents a much lower catalytic onset overpotential and reached higher currents densities at each potential. The controlled-current electrolysis at $10 \mathrm{~mA} . \mathrm{cm}^{-2}$ presented in Figure 9B confirmed this, showing that the amorphous FeP NPs required an overpotential of $230 \mathrm{mV}$, whereas crystalline $\mathrm{FeP}$ and $\mathrm{Fe}_{2} \mathrm{P}$ needed $330 \mathrm{mV}$ and $380 \mathrm{mV}$, respectively. Gas chromatography (GC) carried out during the electrolysis showed that all particles produced $\mathrm{H}_{2}$ at $100 \%$ Faradaic efficiency.

A significantly different behavior was observed in neutral media $\left(\mathrm{Na}_{2} \mathrm{SO}_{4}\right.$ at $1.0 \mathrm{M}$, Figure $9 \mathrm{C}$ and D); while the overall trend on the onset overpotential was kept $\left(\eta_{\mathrm{FeP} \text { amorphous }}<\eta_{\mathrm{FeP} \text { crystalline }}<\eta_{\mathrm{Fe} 2 \mathrm{P} \text { crystalline }}\right)$, the three catalysts presented much smaller differences in activity than in the acidic electrolyte. Catalytic $\mathrm{H}_{2}$ evolution was observed under controlled current electrolysis at $-10 \mathrm{~mA} \cdot \mathrm{cm}^{-2}$ at applied potentials of $-582,-603$ and $654 \mathrm{mV}$ for amorphous $\mathrm{FeP}$, crystalline $\mathrm{FeP}$ and crystalline $\mathrm{Fe}_{2} \mathrm{P}$, respectively. The higher overpotential observed here likely results from the slower kinetics for proton exchange in neutral media. 

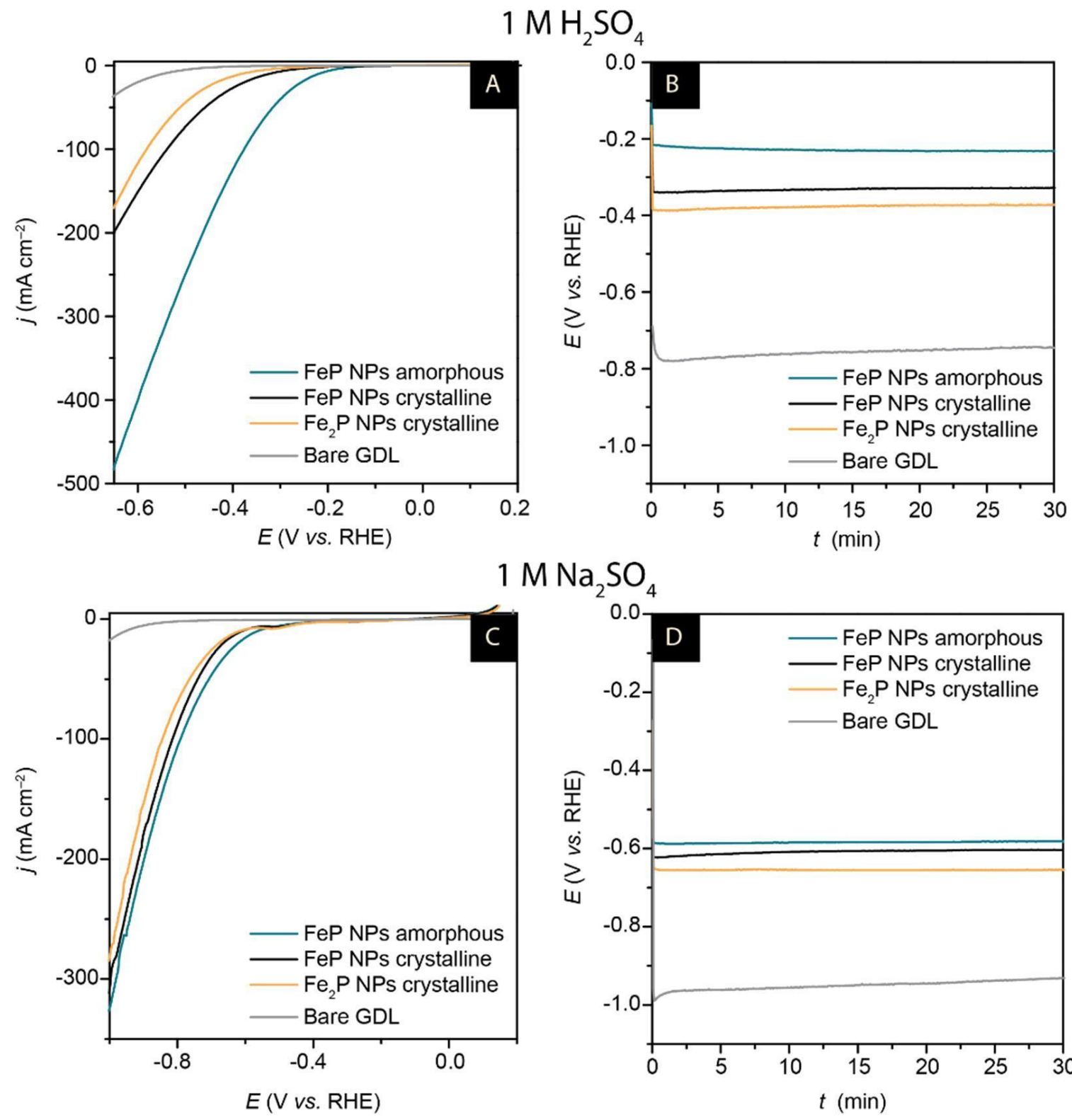

$1 \mathrm{M} \mathrm{Na}_{2} \mathrm{SO}_{4}$

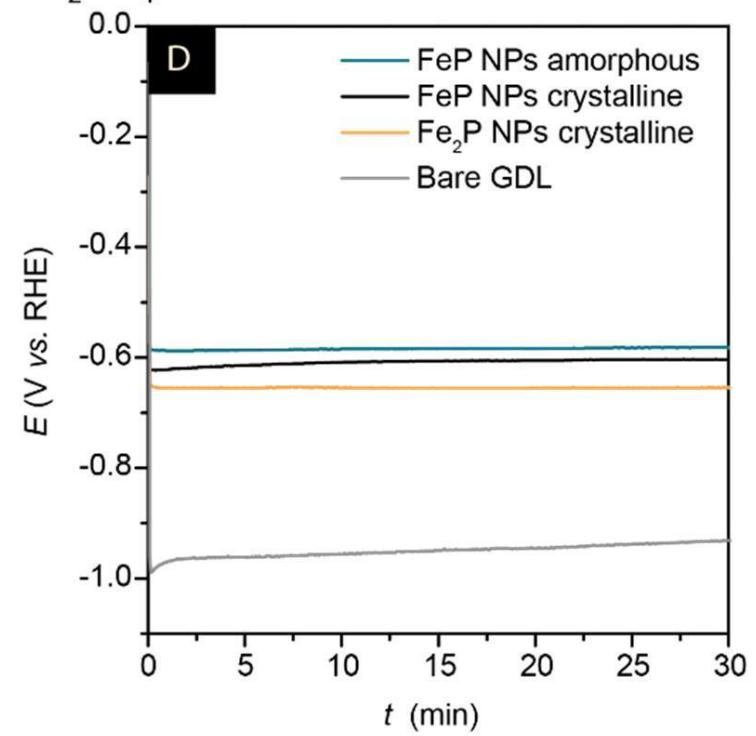

Figure 9: (A) LSVs of $\mathrm{Fe}_{x} \mathrm{P}$ NPs loaded onto GDL electrodes in $1.0 \mathrm{M} \mathrm{H}_{2} \mathrm{SO}_{4}$ at a scan rate of $50 \mathrm{mV} . \mathrm{s}^{-1}$ at room temperature; (B) Controlled-current electrolysis at $-10 \mathrm{~mA} . \mathrm{cm}^{-2}$ of the electrodes in $\mathrm{A}$; (C) and (D) show the analogous experiments performed in $1 \mathrm{M} \mathrm{Na}_{2} \mathrm{SO}_{4}$. In all cases the electrodes were activated by application of $-1.0 \mathrm{~V}$ vs. RHE for 1 hour in their respective electrolysis solutions.

As the average sizes and preparation routes were similar, the differences in activity were ascribed to the nature of the active sites exposed on the nanoparticles surface: the availability 
of the Fe centers, the local structure and bonding around the $\mathrm{Fe}$ center and the $\mathrm{Fe}: \mathrm{P}$ stoichiometry are likely to influence the d-band filling of the inorganic phases. XPS comparison of the fresh powders of nanoparticles does not explain the trend, as all surfaces contain both phosphide and phosphates (Figure S19). Post-mortem analyses of the GDL were also inconclusive due to the low amount of catalysts trapped in the GDL.

Experimentally, the amorphous nanoparticles show a higher activity, similar to that reported for a FeP surface, ${ }^{[8]}$ than the crystalline $\mathrm{FeP}$ and $\mathrm{Fe}_{2} \mathrm{P}$ do. However, detailed comparison with performances showed in the literature, in terms of activity (numbers, potentials) is tricky to provide as each study proposes its own set of experimental conditions (cell design, catalyst support, deposition method, pretreatment, etc.). Advanced modeling by DFT, as well as in situ monitoring of the nanoparticles surface during electrocatalytic measurements, is being considered to rationalize the activity measured, and will be reported in due course. In particular, the electrochemically active surface area of all the nanoparticles should be quantified by further investigation, in order to compare the catalysts based on a similar number of active sites. Besides, as suggested by a recent work on phosphorus-rich phosphides, ${ }^{[13]}$ characterizing the adsorption strength of $\mathrm{H}$ species on the amorphous $v s$. crystalline surface would be of major interest, not only for Fe-based compounds but also for Mo-based ones, for which a strong activity of the amorphous phase was reported. ${ }^{[71]}$ Moreover, in-depth study of the effect of the support as well as the influence of pretreatment under $\mathrm{H}_{2}$ might also lead to optimized efficiency of these catalysts.

\section{Conclusion}

In summary, we designed a unique $\mathrm{P}_{4}(\mathrm{MesCO})_{4}$ molecule that acts as a stoichiometric phosphorus source for the selective synthesis of crystalline $\mathrm{FeP}$ and $\mathrm{Fe}_{2} \mathrm{P}$ nanoparticles. In both cases, the reactions conducted at $250{ }^{\circ} \mathrm{C}$ yielded a hollow morphology characteristic of outward diffusion of the metal during the phosphorus insertion. XPS and PDF analyses were 
then combined to better understand the local order of the materials as well as the reaction mechanism. At a lower temperature of $180{ }^{\circ} \mathrm{C}$, an intermediate amorphous phase was formed both for $x=1$ and $x=2$, with a local structure close to the crystalline equivalent. These assynthesized materials were investigated as electrocatalysts for proton reduction, the most active one being the amorphous FeP. This highlights the relevance of studying amorphous nanoparticles that are often undervalued in catalysis due to a challenging characterization, which was addressed here thanks to the PDF. 


\section{Experimental section}

\subsection{Synthesis of Mesitoylphosphane}

A dry and argon flushed Schlenk flask equipped with a magnetic stirrer was charged with finely divided elemental sodium $(2.35 \mathrm{~g}, \quad 102 \mathrm{mmol}, \quad 3.1$ equivalents $)$ and 1,2dimethoxyethane $(40 \mathrm{~mL})$. Naphthalene $(0.42 \mathrm{~g}, 3.3 \mathrm{mmol}, 0.1$ equivalent $)$ was added to the suspension. The reaction mixture was stirred until it turned deep green. Red phosphorus (1.02 g, $33 \mathrm{mmol}, 1$ equivalent) was added in one portion and the resulting suspension was stirred for 48 hours at room temperature. Leftover sodium was removed with tweezers and the black suspension was cooled to $0^{\circ} \mathrm{C}$ with an ice bath. Tert-butanol $(3.16 \mathrm{~mL}, 2.45 \mathrm{~g}, 33 \mathrm{mmol}$, 1 equivalent) was mixed with $10 \mathrm{~mL}$ dry 1,2-dimethoxyethane in a dropping funnel and subsequently added dropwise to the stirred reaction mixture over 30 minutes. The ice bath was removed and the suspension was stirred for an additional 2 hours at room temperature. Methyl 2,4,6-trimethylbenzoate (5.88 g, $33 \mathrm{mmol}, 1$ equivalent) was added dropwise to the suspension, which was subsequently stirred for 2 hours at room temperature. Formic acid (3.8 $\mathrm{mL}, 4.6 \mathrm{~g}, 100 \mathrm{mmol}, 3.1$ equivalents) was added dropwise to the suspension which was stirred for an additional 30 minutes. The reaction volume was reduced to roughly one third and $n$-hexane $(50 \mathrm{~mL})$ was added. The solids were removed by filtration, washed with $n$ hexane $(20 \mathrm{~mL})$ and the resulting filtrate was dried in vacuo, affording the crude mesitoylphosphane as a yellow oil $(3.85 \mathrm{~g}, 21.3 \mathrm{mmol}, 65 \%$ yield). This crude material was sufficiently pure for the subsequent cyclization step. See Figure S1 and Figure S2 for NMR spectra.

${ }^{31} \mathbf{P}\left\{{ }^{1} \mathbf{H}\right\}-N M R\left(121 \mathrm{MHz}, \mathrm{CDCl}_{3}, \mathrm{ppm}\right): \delta=-51$ (s, enol form); -97.8 (s, keto form).

\subsection{Synthesis of $\mathrm{P}_{4}(\mathrm{MesCO})_{4}$}

A dry and argon flushed Schlenk flask equipped with a magnetic stirrer was charged with THF (100mL) and mesitoylphosphane (3.6 g, $20 \mathrm{mmol}, 1$ equivalent). The mixture was stirred 
vigorously and hexachloroethane $(4.73 \mathrm{~g}, 20 \mathrm{mmol}, 1$ equivalent) was added in one portion. Triethylamine (4.04 g, $40 \mathrm{mmol}, 2$ equivalents) was added dropwise over 15 minutes. The resulting white suspension was stirred for 16 hours at room temperature before removing all volatiles in vacuo. Diethylether $(50 \mathrm{~mL})$ was added slowly to the residue and the resulting solid was collected on a frit, washed twice with deionized water $(2 \times 100 \mathrm{~mL})$ and once with diethylether $(50 \mathrm{~mL})$. The solid was dried in vacuo at $150^{\circ} \mathrm{C}$, affording $\mathrm{P}_{4}(\mathrm{MesCO})_{4}$ as a pale yellow powder $(0.53 \mathrm{~g}, 3 \mathrm{mmol}, 15 \%$ yield $)$.

Melting Point (DTA): $244.6^{\circ} \mathrm{C}$ (decomp.)

${ }^{1} \mathbf{H}-\mathbf{N M R}\left(300 \mathrm{MHz}, \mathrm{CDCl}_{3}, \mathrm{ppm}\right): \delta=6.71(\mathrm{~s}, 8 \mathrm{H}, \mathrm{CH}) ; 2.33\left(\mathrm{~s}, 12 \mathrm{H}, p-\mathrm{CH}_{3}\right) ; 2.00(\mathrm{~s}, 24 \mathrm{H}$, $\left.o-\mathrm{CH}_{3}\right)$.

${ }^{13} \mathbf{C}\left\{{ }^{1} \mathbf{H}\right\}$-NMR $\left(75 \mathrm{MHz}, \mathrm{CDCl}_{3}, \mathrm{ppm}\right): \delta=224.6(\mathrm{~m}, C \mathrm{O}) ; 139.9\left(\mathrm{~s}, C_{\mathrm{para}}\right) ; 136.5\left(\mathrm{~m}, C_{\mathrm{ipso}}\right)$; 133.9 (s, $\left.C_{\text {ortho}}\right) ; 128.9(\mathrm{~s}, \mathrm{CH}) ; 21.3\left(\mathrm{~s}, p-\mathrm{CH}_{3}\right) ; 20.0$ (quin, $\left.\mathrm{J}_{\mathrm{PC}}=3.3 \mathrm{~Hz}, o-\mathrm{CH}_{3}\right)$.

${ }^{31} \mathbf{P}\left\{{ }^{1} \mathbf{H}\right\}-N M R\left(121 \mathrm{MHz}, \mathrm{CDCl}_{3}, \mathrm{ppm}\right): \delta=-44.7(\mathrm{~s})$.

FTIR (ATR, 298K, cm ${ }^{-1}$ ): v = 2948 (w), 2915 (w), 2094 (br), 1655 (s), 1605 (m), 1448 (m), $1418(\mathrm{w}), 1377$ (m), 1294 (w), 1201 (m), $1139(\mathrm{~m}), 1033$ (m), $955(\mathrm{w}), 865(\mathrm{~m}), 843$ (s), 725 (m), $676(\mathrm{~m}), 616(\mathrm{~s}), 571(\mathrm{w}), 543(\mathrm{~m}), 508(\mathrm{w}), 472(\mathrm{w}), 442(\mathrm{w}), 412(\mathrm{w})$.

\subsection{Synthesis of $\mathrm{Fe}_{x} \mathrm{P}$ nanoparticles}

A $100 \mathrm{~mL}$ three-necked round bottom flask was charged with oleylamine (60.8 mmol, $16.3 \mathrm{~g}$ ) and 1-octadecene $(1.1 \mathrm{mmol}, 0.3 \mathrm{~g})$. The mixture was degassed at $120^{\circ} \mathrm{C}$ under dynamic vacuum for $30 \mathrm{~min}$. It was then put back under $\mathrm{N}_{2}$ and heated up to $180{ }^{\circ} \mathrm{C}$. $\mathrm{Fe}(\mathrm{CO})_{5}$ (5.2 mmol, $0.7 \mathrm{~mL}$ ) was added and the solution was stirred at this temperature for $20 \mathrm{~min}$. The black suspension was cooled down to room temperature. One may note that the $\mathrm{P}_{4}(\mathrm{MesCO})_{4}$ stoichiometry was calculated assuming a quantitative yield of the $\mathrm{Fe}(0) \mathrm{NPs}$ synthesis ${ }^{[38,72]}$, leading to a slight but over-evaluation of the P-source amount in the following step. 
The desired amount of $\mathrm{P}_{4}(\mathrm{MesCO})_{4}$ was then added (for instance, for FeP: $1.3 \mathrm{mmol}, 0.9 \mathrm{~g}$ ) and the mixture was degassed by three successive vacuum/ $\mathrm{N}_{2}$ cycles $(1 \mathrm{~min}$ per cycle). The solution was heated up to $180^{\circ} \mathrm{C}$ or $250{ }^{\circ} \mathrm{C}$ under $\mathrm{N}_{2}$ and stirred for an additional $90 \mathrm{~min}$. It was finally cooled down to room temperature by removing the heating mantle. The black suspension was transferred in two centrifuge tubes and dispersed in $n$-hexane $(5 \mathrm{~mL})$ and acetone was added $(20 \mathrm{~mL})$. The black solid was precipitated out by centrifugation process (6000 rpm, $10 \mathrm{~min})$ and washed at least two times with a $n$-hexane/acetone (1:5) mixture. It was finally dried under $\mathrm{N}_{2}$ flux to yield $\mathrm{FeP}$ nanoparticles.

The same procedure was followed when $\mathrm{Fe}_{4} \mathrm{P}, \mathrm{Fe}_{3} \mathrm{P}$ and $\mathrm{Fe}_{2} \mathrm{P}$ stoichiometry were targeted.

\subsection{Electrode preparation}

Inks of $\mathrm{FeP} / \mathrm{Fe}_{2} \mathrm{P}$ nanoparticles were prepared by sonication in the presence of isopropanol (1 mg per $100 \mu \mathrm{L}$ ) until a homogeneous black suspension was formed. The suspension was dropcasted onto a $1 \mathrm{~cm}^{2}$ gas diffusion layer electrode (Sigracet 29 AA, Fuel Cell Store) in aliquots of $50 \mu \mathrm{L} \times 4$. Each aliquot was allowed to dry before the proceeding aliquot was added.

Before use of the electrodes, activation of the particles was undertaken by application of 1.0 V vs. RHE in the electrolyte solution for 1 hour.

\subsection{Electrochemical performance testing}

Electrocatalytic measurements and constant potential electrolysis were carried out using a Bio-logic SP300 potentiostat. Ohmic drop correction at $80 \%$ was undertaken on linear sweep voltammograms. A H-type cell was used with each compartment separated by a Nafion membrane (Alfa Aesar, N-115) with an inter-electrode distance of $6 \mathrm{~cm}$ between the working and $\mathrm{Pt}$ counter and an $\mathrm{Ag} / \mathrm{AgCl}$ reference (saturated $\mathrm{KCl}$ ) placed at $0.5 \mathrm{~cm}$ from the working. 1.0 $\mathrm{M} \mathrm{H}_{2} \mathrm{SO}_{4}$ (Sigma-Aldrich, $99.9 \%$ ) or $1.0 \mathrm{M} \mathrm{Na}_{2} \mathrm{SO}_{4}$ aqueous solutions was used as both 
anolyte and catholyte, the catholyte being Ar-saturated preceding the experiment. During the electrolysis, Ar was constantly bubbled at $5 \mathrm{~mL} \cdot \mathrm{min}^{-1}$ through a frit at the bottom of the cathodic chamber. Generated $\mathrm{H}_{2}$ and excess Ar were flowed to the gaseous inlet of a gas chromatograph for online measurement.

Potentials are reported against the Reversible Hydrogen Electrode (RHE) according to the relationship $E v s . \mathrm{RHE}=E v s . \mathrm{Ag} / \mathrm{AgCl}+0.197+0.059 * \mathrm{pH}$.

\section{6 $\mathrm{H}_{2}$ characterization}

$\mathrm{H}_{2}$ was analyzed by gas chromatography (GC, Multi-Gas Analyzer \#5 SRI Instruments), equipped with Haysep D and MoleSieve $5 \AA$ columns, thermal conductivity detector (TCD) and flame ionization detector (FID) with methanizer using $\mathrm{Ar}$ as a carrier gas. The GC was calibrated using a standard gas mixture containing 2500 ppm of $\mathrm{H}_{2}$ in $\mathrm{CO}_{2}$ (Messer). Faradaic efficiencies (FE) were calculated according to the following formula:

$$
F E_{\text {product }}=\frac{2 * n_{H 2} * F}{Q}
$$

Where $\mathrm{n}_{\mathrm{H} 2}(\mathrm{~mol})$ is the quantity of analyzed product, $\mathrm{F}$ is the Faraday's constant equal to 96485 C.mol ${ }^{-1}$ and Q is the corresponding passed charge.

\section{Acknowledgements}

This work was supported by Sorbonne Université, CNRS, and the Collège de France. F. D. thanks the Fondation du Collège de France for financial support. The detector used for the PDF measurements was bought thanks to contributions of ANR OxySUN (ANR-16-CE090005) and of IMPC. Christophe Méthivier and Antoine Miche, from LRS, are acknowledged for the XPS measurements. Michael Wörle from the Small Molecule Crystallography Center at ETH Zürich is acknowledged for his contribution to X-Ray diffraction structure solution. D.W. was supported by an Idex PSL grant (ANR-10-IDEX-001-02 PSL $\star$ ), the Fondation du 
Collège de France and the Marie Curie PRESTIGE Fellowship programme. S.L. was funded by the Corps des Ponts, des Eaux et des Forêts.

\section{References}

[1] S. Carenco, D. Portehault, C. Boissière, N. Mézailles, C. Sanchez, Chem. Rev. 2013, $113,7981-8065$.

[2] Y. Shi, B. Zhang, Chem. Soc. Rev. 2016, 45, 1529-1541.

[3] S. L. Brock, S. C. Perera, K. L. Stamm, Chemistry 2004, 10, 3364-71.

[4] P. Reiss, M. Carrière, C. Lincheneau, L. Vaure, S. Tamang, Chem. Rev. 2016, 116, $10731-10819$.

[5] D. Yang, J. Zhu, X. Rui, H. Tan, R. Cai, H. E. Hoster, D. Y. W. Yu, H. H. Hng, Q. Yan, ACS Appl. Mater. Interfaces 2013, 5, 1093-1099.

[6] F. Gillot, S. Boyanov, L. Dupont, M.-L. Doublet, M. Morcrette, L. Monconduit, J.-M. Tarascon, Chem. Mater. 2005, 17, 6327-6337.

[7] S. Carenco, C. Surcin, M. Morcrette, D. Larcher, N. Mézailles, C. Boissière, C. Sanchez, Chem. Mater. 2012, 24, 688-697.

[8] J. F. Callejas, J. M. McEnaney, C. G. Read, J. C. Crompton, A. J. Biacchi, E. J. Popczun, T. R. Gordon, N. S. Lewis, R. E. Schaak, ACS Nano 2014, 8, 11101-11107.

[9] G. L. Savithra, R. H. Bowker, B. A. Carrillo, M. E. Bussell, S. L. Brock, G. H. L. Savithra, L. Stephanie, Chem. Mater. 2013, 25, 825-833.

[10] S. Carenco, A. Leyva-Pérez, P. Concepción, C. Boissière, N. Mézailles, C. Sanchez, A. Corma, Nano Today 2012, 7, 21-28.

[11] G. Cho, H. Kim, Y. S. Park, Y. Hong, Int. J. Hydrogen Energy 2018, 43, 1132611334.

[12] T. Matsumoto, H.-C. Chang, M. Wakizaka, S. Ueno, A. Kobayashi, A. Nakayama, T. 
Taketsugu, M. Kato, J. Am. Chem. Soc. 2013, 135, 8646-8654.

[13] J. Cai, Y. Song, Y. Zang, S. Niu, Y. Wu, Y. Xie, X. Zheng, Y. Liu, Y. Lin, X. Liu, et al., Sci. Adv. 2020, 6, eaaw8113.

[14] K. Liu, C. Zhang, Y. Sun, G. Zhang, X. Shen, F. Zou, H. Zhang, Z. Wu, E. C. Wegener, C. J. Taubert, et al., ACS Nano 2018, 12, 158-167.

[15] B. Zhang, Y. H. Lui, H. Ni, S. Hu, Nano Energy 2017, 38, 553-560.

[16] E. Hu, Y. Feng, J. Nai, D. Zhao, Y. Hu, X. W. (David) Lou, Energy Environ. Sci. 2018, $11,872-880$.

[17] P. Zhang, X. F. Lu, J. Nai, S. Zang, X. W. (David) Lou, Adv. Sci. 2019, 6, 1900576.

[18] Y. Xu, R. Wu, J. Zhang, Y. Shi, B. Zhang, Chem. Commun. 2013, 49, 6656.

[19] C. Y. Son, I. H. Kwak, Y. R. Lim, J. Park, Chem. Commun. 2016, 52, 2819-2822.

[20] M. Mohiuddin, A. Zavabeti, F. Haque, A. Mahmood, R. S. Datta, N. Syed, M. W. Khan, A. Jannat, K. Messalea, B. Y. Zhang, et al., J. Mater. Chem. A 2020, 8, 27892797.

[21] X. F. Lu, L. Yu, X. W. (David) Lou, Sci. Adv. 2019, 5, eaav6009.

[22] J. Su, J. Zhou, L. Wang, C. Liu, Y. Chen, Sci. Bull. 2017, 62, 633-644.

[23] L. Tian, X. Yan, X. Chen, ACS Catal. 2016, 6, 5441-5448.

[24] S. Yao, V. Forstner, P. W. Menezes, C. Panda, S. Mebs, E. M. Zolnhofer, M. E. Miehlich, T. Szilvási, N. Ashok Kumar, M. Haumann, et al., Chem. Sci. 2018, 9, 8590_ 8597.

[25] H. G. Von Schnering, W. Hoenle, Chem. Rev. 1988, 88, 243-273.

[26] Z. Zhao, L. Liu, S. Zhang, T. Yu, F. Li, G. Yang, RSC Adv. 2017, 7, 15986-15991.

[27] P. Jiang, Q. Liu, Y. Liang, J. Tian, A. M. Asiri, X. Sun, Angew. Chemie - Int. Ed. 2014, $53,12855-12859$.

[28] Z. Zhang, J. Hao, W. Yang, B. Lu, J. Tang, Nanoscale 2015, 7, 4400-4405. 
[29] D. Y. Chung, S. W. Jun, G. Yoon, H. Kim, J. M. Yoo, K.-S. Lee, T. Kim, H. Shin, A. K. Sinha, S. G. Kwon, et al., J. Am. Chem. Soc. 2017, 139, 6669-6674.

[30] E. Muthuswamy, S. L. Brock, J. Am. Chem. Soc. 2010, 132, 15849-51.

[31] J. Liu, M. Meyns, T. Zhang, J. Arbiol, A. Cabot, A. Shavel, Chem. Mater. 2018, 30, $1799-1807$.

[32] J. Wang, Q. Yang, Z. Zhang, S. Sun, Chem. - A Eur. J. 2010, 16, 7916-7924.

[33] A. E. Henkes, R. E. Schaak, Chem. Mater. 2007, 19, 4234-4242.

[34] E. Muthuswamy, P. R. Kharel, G. Lawes, S. L. Brock, ACS Nano 2009, 3, 2383-2393.

[35] A. A. Guzelian, J. E. B. Katari, A. V. Kadavanich, U. Banin, K. Hamad, E. Juban, A. P. Alivisatos, R. H. Wolters, C. C. Arnold, J. R. Heath, J. Phys. Chem. 1996, 100, 7212 7219.

[36] L. Li, P. Reiss, J. Am. Chem. Soc. 2008, 130, 11588-9.

[37] S. C. Perera, P. S. Fodor, G. M. Tsoi, L. E. Wenger, S. L. Brock, Chem. Mater. 2003, $15,4034-4038$.

[38] S. Carenco, Y. Hu, I. Florea, O. Ersen, C. Boissière, N. Mézailles, C. Sanchez, Chem. Mater. 2012, 24, 4134-4145.

[39] S. Carenco, Y. Hu, I. Florea, O. Ersen, C. Boissière, C. Sanchez, N. Mézailles, Dalt. Trans. 2013, 42, 12667-74.

[40] S. Mourdikoudis, R. M. Pallares, N. T. K. Thanh, Nanoscale 2018, 10, 12871-12934.

[41] T. Proffen, S. J. L. Billinge, T. Egami, D. Louca, Zeitschrift für Krist. - Cryst. Mater. 2003, 218, 132-143.

[42] S. J. L. Billinge, J. Solid State Chem. 2008, 181, 1695-1700.

[43] K. Galliez, P. Deniard, P.-E. Petit, D. Lambertin, F. Bart, S. Jobic, J. Appl. Crystallogr. 2014, 47, 552-560.

[44] C. A. Reiss, A. Kharchenko, M. Gateshki, Zeitschrift für Krist. 2012, 227, 257-261. 
[45] V. Kelsen, A. Meffre, P.-F. Fazzini, P. Lecante, B. Chaudret, ChemCatChem 2014, 6, $1714-1720$.

[46] O. Masson, A. Berghout, E. Béchade, J. Jouin, P. Thomas, T. Asaka, K. Fukuda, Sci. Technol. Adv. Mater. 2017, 18, 644-653.

[47] G. Confalonieri, M. Dapiaggi, M. Sommariva, M. Gateshki, A. N. Fitch, A. Bernasconi, Powder Diffr. 2015, 30, S65-S69.

[48] D. Vaknin, W. Bu, A. Travesset, J. Chem. Phys. 2008, 129, 044504.

[49] C. J. Benmore, ISRN Mater. Sci. 2012, 2012, 1-19.

[50] A. C. Wright, Glas. Phys. Chem. 1998, 24, 148-179.

[51] R. K. Biswas, P. Khan, S. Mukherjee, A. K. Mukhopadhyay, J. Ghosh, K. Muraleedharan, J. Non. Cryst. Solids 2018, 488, 1-9.

[52] A. R. Sheth, S. Bates, F. X. Muller, D. J. W. Grant, Cryst. Growth Des. 2005, 5, 571578.

[53] S. J. L. Billinge, M. G. Kanatzidis, Chem. Commun. 2004, 749.

[54] A. S. Masadeh, E. S. Božin, C. L. Farrow, G. Paglia, P. Juhas, S. J. L. Billinge, A. Karkamkar, M. G. Kanatzidis, Phys. Rev. B - Condens. Matter Mater. Phys. 2007, 76, $1-11$.

[55] A. Eibel, M. Schmallegger, M. Zalibera, A. Huber, Y. Bürkl, H. Grützmacher, G. Gescheidt, Eur. J. Inorg. Chem. 2017, 2017, 2469-2478.

[56] K. Dietliker, T. Jung, J. Benkhoff, H. Kura, A. Matsumoto, H. Oka, D. Hristova, G. Gescheidt, G. Rist, Macromol. Symp. 2004, 217, 77-98.

[57] F. Knoch, R. Appel, V. Barth, Zeitschrift für Krist. - Cryst. Mater. 1996, 211, 343-344.

[58] M. Podewitz, J. D. van Beek, M. Wörle, T. Ott, D. Stein, H. Rüegger, B. H. Meier, M. Reiher, H. Grützmacher, Angew. Chemie 2010, 122, 7465-7469.

[59] S. Peng, C. Wang, J. Xie, S. Sun, J. Am. Chem. Soc. 2006, 128, 10676-7. 
[60] C. E. Myers, H. F. Franzen, J. W. Anderegg, Inorg. Chem. 1985, 24, 1822-1824.

[61] T. P. Moffat, R. M. Latanision, R. R. Ruf, Electrochim. Acta 1995, 40, 1723-1734.

[62] P.-H. Lo, J. Electrochem. Soc. 1995, 142, 91.

[63] Y. Barbaux, M. Dekiouk, D. Le Maguer, L. Gengembre, D. Huchette, J. Grimblot, Appl. Catal. A Gen. 1992, 90, 51-60.

[64] W. Wang, M. Dahl, Y. Yin, Chem. Mater. 2013, 25, 1179-1189.

[65] P. Debye, H. Menke, Phys. Zeitschrift 1930, 31, 798-801.

[66] O. Masson, P. Thomas, J. Appl. Crystallogr. 2013, 46, 461-465.

[67] V. Petkov, Mater. Today 2008, 11, 28-38.

[68] P. Juhás, T. Davis, C. L. Farrow, S. J. L. Billinge, J. Appl. Crystallogr. 2013, 46, 560566.

[69] C. L. Farrow, P. Juhas, J. W. Liu, D. Bryndin, E. S. Boin, J. Bloch, T. Proffen, S. J. L. Billinge, J. Phys. Condens. Matter 2007, 19, 335219.

[70] C. C. L. McCrory, S. Jung, I. M. Ferrer, S. M. Chatman, J. C. Peters, T. F. Jaramillo, J. Am. Chem. Soc. 2015, 137, 4347-4357.

[71] J. M. McEnaney, J. C. Crompton, J. F. Callejas, E. J. Popczun, A. J. Biacchi, N. S. Lewis, R. E. Schaak, Chem. Mater. 2014, 26, 4826-4831.

[72] L.-M. Lacroix, N. F. Huls, D. Ho, X. Sun, K. Cheng, S. Sun, Nano Lett. 2011, 11, $1641-5$. 


\section{Table of Content Graphic}

Phase-controlled $\mathrm{FeP}$ and $\mathrm{Fe}_{2} \mathrm{P}$ nanoparticles are prepared using a cyclophosphane at $250{ }^{\circ} \mathrm{C}$. At $180^{\circ} \mathrm{C}$, amorphous compounds are formed yet they present the local structure of the crystalline phases. Amorphous FeP is more active in HER than the corresponding crystalline nanocatalysts.

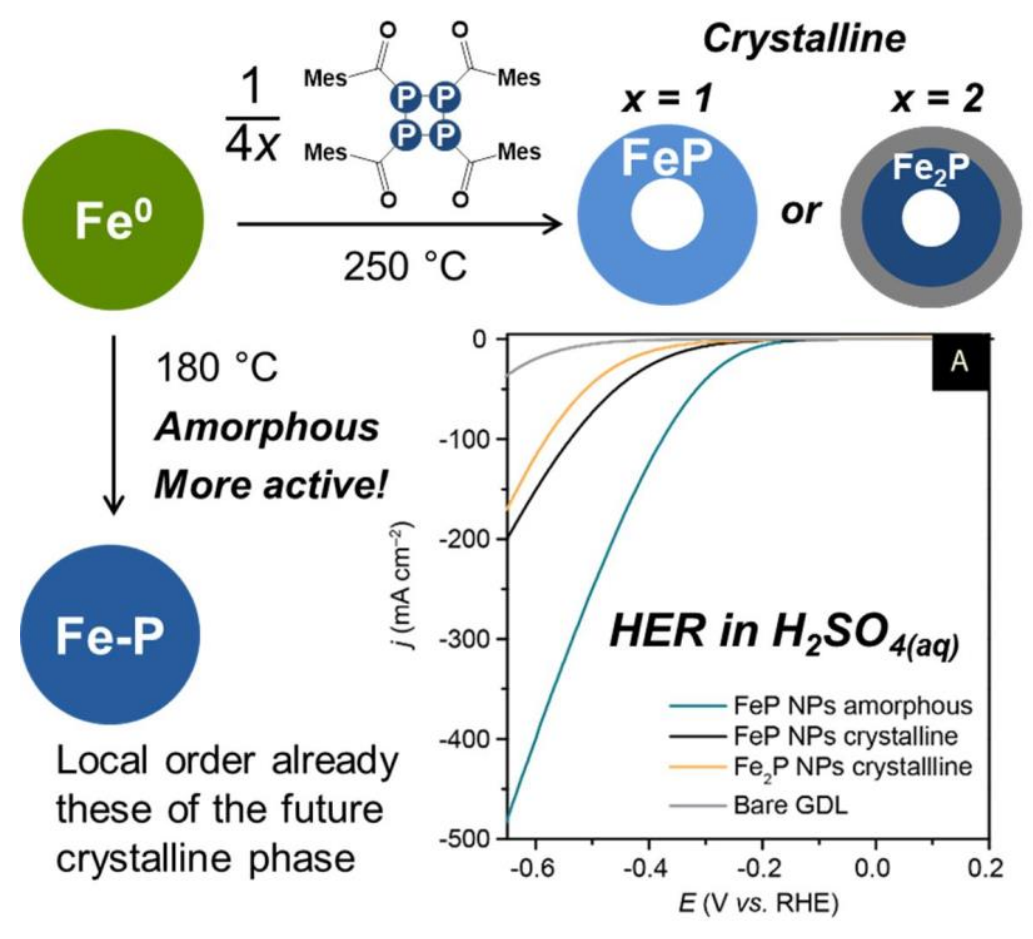

